\title{
The impact of prenatal vitamin $A$ and zinc supplementation on growth of children up to 2 years of age in rural Java, Indonesia
}

\author{
Endy P Prawirohartono ${ }^{1, *}$, Lennarth Nyström ${ }^{2}$, Anneli Ivarsson ${ }^{2}$, Hans Stenlund ${ }^{2}$ and \\ Torbjörn Lind ${ }^{3}$ \\ 'Department of Child Health, Medical School, Gadjah Mada University, Sardjito Hospital, Jalan Kesehatan \\ no. 1, Sekip, Yogyakarta 55284, Indonesia: ${ }^{2}$ Division of Epidemiology and Global Health Sciences, \\ Department of Public Health and Clinical Medicine, Umeå University, Sweden: ${ }^{3}$ Division of Pediatrics, \\ Department of Clinical Sciences, Umeå University, Sweden
}

Submitted 16 April 2010: Accepted 31 March 2011: First published online 23 June 2011

\begin{abstract}
Objective: To determine whether prenatal vitamin A and/or Zn supplementation affects postnatal growth.

Design: Follow-up of a randomized controlled trial monitoring growth in children from birth up to 24 months of age.

Setting: Central Java, Indonesia.

Subjects: Children ( $n$ 343) of mothers participating in a double-blinded, randomized controlled study of vitamin A and/or Zn supplementation during pregnancy. We report the effects of prenatal supplementation on infant growth, measured as weight-for-age $Z$-scores (WAZ), height-for-age $Z$-scores (HAZ) and weight-for-height $Z$-scores (WHZ ), from 0 to 24 months, as well as differences in growth faltering among the supplementation groups.

Results: For HAZ, the absolute differences between the vitamin A-only and vitamin $\mathrm{A}+\mathrm{Zn}$ groups at 3 and 9 months were $0.34 \mathrm{sD}$ and $0.37 \mathrm{sD}$, respectively, and the absolute difference between the vitamin A-only and Zn-only groups at 18 months was 0.31 SD. Compared with placebo, none of the supplements affected growth. Defining growth faltering as a downward crossing of two or more major percentile lines, $50-75 \%$ of the children were found to be growth faltering within 9 months of age, whereas $17 \%$ and $8 \%$ scored $<-2$ sD for WAZ and HAZ, respectively. Prenatal supplementation did not reduce the prevalence of growth faltering.

Conclusions: Prenatal vitamin A supplementation had a small but significant effect on postnatal growth of children's length until 18 months of age compared with supplementation with either vitamin A + Zn or Zn alone, but not compared with placebo. It had no effects on other anthropometric measures and did not reduce the prevalence of growth faltering. Future studies should duplicate these findings before recommendations can be made.
\end{abstract}

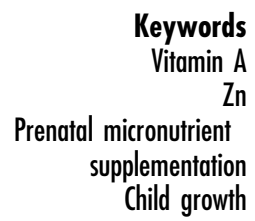

Keywords

Zn

Child growth
Malnutrition and growth faltering remain common among children in developing countries. In 2005, intra-uterine growth retardation and severe wasting and stunting were responsible for $2 \cdot 2$ million deaths and for $21 \%$ of disability-adjusted life years in children under 5 years of age globally ${ }^{(1)}$. In rural Indonesia in $2007,22 \%$ of under 5-year-old children were moderately or severely wasted, whereas the prevalence of moderate or severe stunting was $66 \%{ }^{(2)}$. The process of malnutrition begins early and has adverse short- and long-term effects on child morbidity and mortality ${ }^{(3)}$, including poor subsequent growth ${ }^{(4)}$ and cognitive and behavioural development ${ }^{(5)}$, as well as increased risk of adult chronic diseases including diabetes mellitus, CHD and stroke ${ }^{(6)}$. A number of prenatal factors (e.g. low maternal height ${ }^{(7)}$; inadequate intake of nutrients, especially micronutrients, during pregnancy $^{(8)}$; infection ${ }^{(9)}$; high caffeine consumption ${ }^{(10,11)}$; and smoking ${ }^{(12)}$ ) have been shown to be related to stunting in children. The immediate factors related to wasting are insufficient supply of protein, energy and micronutrients or severe or frequent infections, especially diarrhoea. The underlying factors are household food insecurity, insufficient child and maternal care, ill health and an unhealthy environment ${ }^{(13)}$.

Consequently, actions to prevent malnutrition and growth faltering in children should begin as early as possible, perhaps even during pregnancy. Prenatal micronutrient supplementation, especially with $\mathrm{Zn}$, vitamin A and Fe, has attracted attention, as these micronutrients have 
possible benefits for both the mother and infant. Pregnant women in developing countries show a high prevalence of micronutrient deficiencies ${ }^{(14)}$. However, studies on prenatal micronutrient supplementation and child growth have yielded conflicting results. Supplementing pregnant women with a multiple micronutrient preparation led to significantly increased fetal growth in one study, whereas another study showed similar effects from $\mathrm{Zn}$ supplementation alone and a third study showed no effect on birth size ${ }^{(8,15,16)}$.

Micronutrient deficiencies are still prevalent among pregnant women in Indonesia. In Purworejo district, Central Java, which was the setting of the present study, $5 \%$ of pregnant women were vitamin A deficient (serum retinol $<0.7 \mu \mathrm{mol} / \mathrm{l}$ ), with $83 \%$ of these women having a dietary intake of vitamin A lower than the Indonesian RDA (700 retinol equivalents $(\mathrm{RE}))^{(17)}$. Zn deficiency measured as $\mathrm{S}-\mathrm{Zn}$ $<10 \cdot 7 \mu \mathrm{mol} / 1$ affected $62 \%$ of pregnant women ${ }^{(17)}$. It should be noted that $\mathrm{Zn}$ requirements are higher during pregnancy, when approximately half of the absorbed $\mathrm{Zn}$ is deposited in the growing fetus and approximately a quarter is deposited in the uterus. Furthermore, S-Zn levels are physiologically lower as a result of haemodilution, lower levels of $\mathrm{Zn}$ binding protein and hormonal changes. The lower $\mathrm{Zn}$ concentrations seen among pregnant women in Purworejo district may reflect these physiological changes, although increased requirements in combination with low bioavailability of $\mathrm{Zn}$ in the diet also cause $\mathrm{Zn}$ deficiency.

Fe deficiency is the third common micronutrient deficiency, with approximately $50 \%$ of pregnant women in Purworejo being Fe deficient and 19\% having Fe-deficiency anaemia, although the use of antenatal Fe supplementation is widespread ${ }^{(17)}$. Among pre-pregnant women, $17 \%$ had chronic energy deficiency (BMI $<18 \cdot 4 \mathrm{~kg} / \mathrm{m}^{2}$ ), $10 \%$ were obese and $79 \%$ did not meet the international recommendations for weight gain during pregnancy, contributing to adverse health outcomes for both mothers and newborns ${ }^{(18)}$

On the basis of the high prevalence of growth faltering, with its serious impact on children's health, growth and development in the future, we sought to assess the effects of $\mathrm{Zn}$, vitamin A or vitamin $\mathrm{A}+\mathrm{Zn}$ supplementation in pregnant women on child growth and the possible prevention of growth faltering up to 2 years of age in a rural area in Indonesia.

\section{Participants and methods}

\section{Study design and participants}

We conducted the present study in Purworejo district, Central Java, Indonesia, which in 1994 (at the beginning of the study) had a total population of 729825 . The study was coordinated by the Community Health and Nutrition Research Laboratories (CHN-RL) at the Faculty of Medicine, Gadjah Mada University, Yogyakarta, Indonesia, in collaboration with the Indonesian Ministry of Health.
Through a surveillance system we had access to 25067 women of child-bearing age (Fig. 1). Out of 5736 pregnant women, 2735 women at a gestational age of $\geq 17$ weeks were not eligible for a supplementation study. Of the remaining 3001 pregnant women, 828 were excluded for various reasons. Therefore, 2173 women at a gestational age of $<17$ weeks were included in the community-based, individually randomized, placebo-controlled and doubleblinded study aiming to evaluate the impact of supplementation (vitamin $\mathrm{A}, \mathrm{Zn}$, vitamin $\mathrm{A}+\mathrm{Zn}$ ) on maternal morbidity and pregnancy. All participants gave their informed consent. The study was called the Zibuvita Study and was conducted from September 1995 to December 1999.

Infants born within the study period were, after approval of caregivers, included in one of two follow-up studies on children, the Zinak and Pronak studies. The Zinak Study was a double-blinded, randomized and controlled study aiming to evaluate the effect of supplementation of infants with $\mathrm{Zn}$ and/or Fe on their growth and morbidity from 6 to 12 months of age ${ }^{(19,20)}$. The Pronak Study was an observational study monitoring children from birth onwards with respect to growth and development, feeding practices and morbidity.

The data generation process is illustrated in Fig. 1. Out of 1956 live births in the Zibuvita Study, 680 and 380 infants, whose mothers or caregivers gave consent and who could be followed up after the civil disruption experienced in Indonesia following the Asian economic crisis, were recruited to the Zinak Study and the Pronak Study, respectively. The disruption decreased staff size and data collection activities. Out of 1956 infants in the Zibuvita Study, 896 (46\%) could not be followed up because of the effects of the economic crisis affecting Indonesia from 1997 onwards. Out of the 380 infants in the Pronak Study, 108 were excluded because of missing data. Consequently, in the follow-up we included 272 children from the Pronak Study and all children allocated to the placebo group in the Zinak Study $(n 71)$. To avoid the unwanted effects of postnatal supplementation on outcomes, we excluded children in the Zinak Study who received supplementation ( $n$ 609). Thus, we finally analysed 343 children.

The smallest difference between the supplementation and placebo groups with regard to weight-for-age $Z$-score (WAZ) and height-for-age $Z$-score (HAZ) that could be detected $(\alpha=0 \cdot 05,1-\beta=0 \cdot 80)$ with the present sample size was $0 \cdot 4$.

\section{Prenatal supplementation in the Zibuvita Study}

The micronutrient capsules given to the pregnant mothers from the date of inclusion in the study until delivery contained either $2400 \mathrm{RE}$ of vitamin A as retinyl palmitate or $20 \mathrm{mg}$ of $\mathrm{ZnSO}_{4}$, or the same dose of both vitamin A and $\mathrm{ZnSO}_{4}$, or placebo. All capsules also contained $2 \mathrm{mg}$ of DL- $\alpha$-tocopherol as an antioxidant and $350 \mathrm{mg}$ of soyabean oil, $20 \mathrm{mg}$ of beeswax and $8 \mathrm{mg}$ of lecithin as capsule filler. Mothers were randomly allocated in a 1:1:1:1 


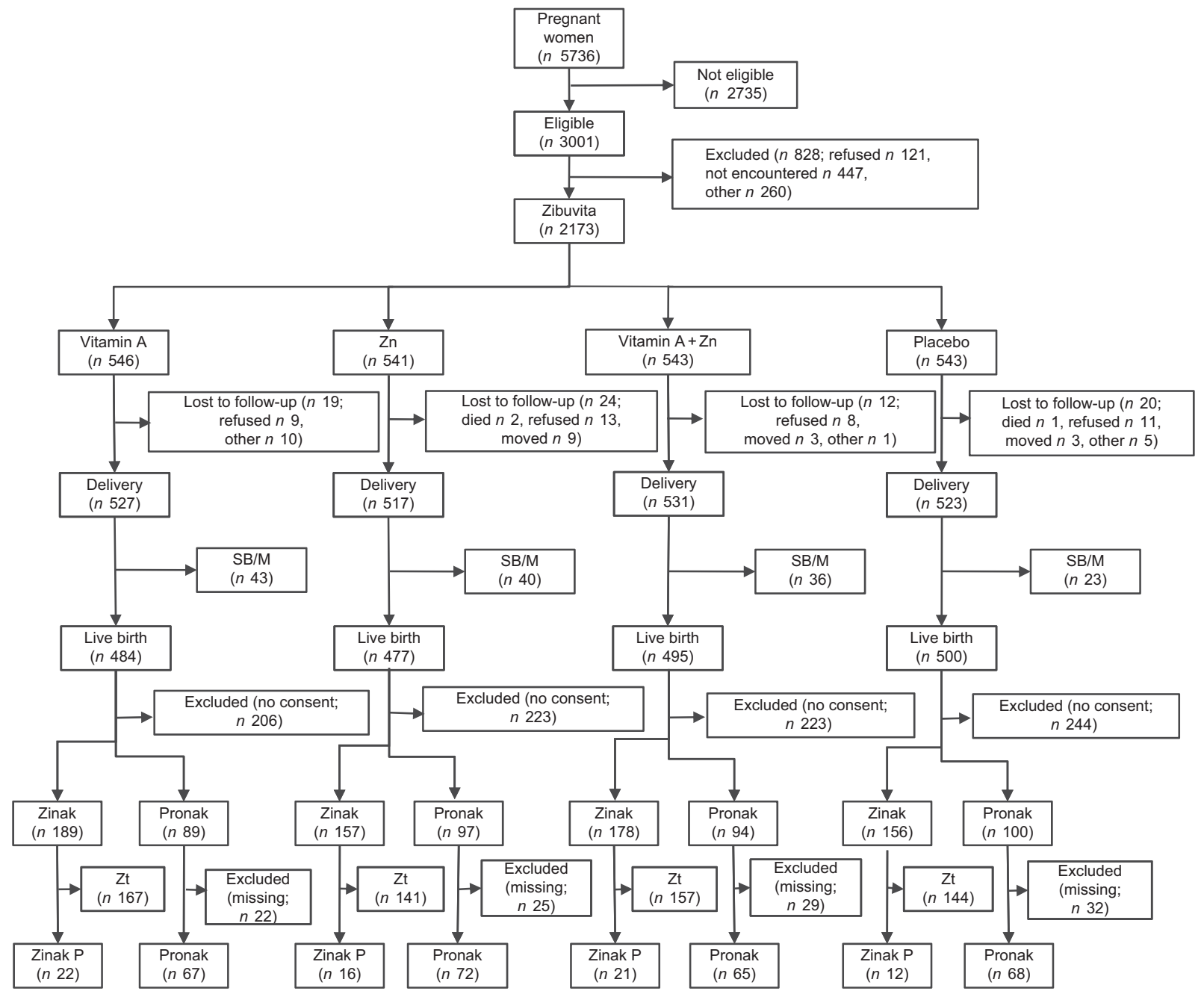

Fig. 1 The selection process showing selection of pregnant women recruited to the Zibuvita, Zinak and Pronak studies and their offspring included in the data analysis (SB, stillbirth; M, miscarriage; Zt, Zinak therapy: Fe and Zn groups; Zinak P, Zinak placebo group)

ratio in blocks of twelve on the basis of a list of treatment numbers derived from a pseudo-random number generated using the SAS statistical software package version 5.0 (SAS Institute Inc., Cary, NC, USA). The treatment allocation sequence was prepared and held at the University of Newcastle, New South Wales, Australia. All investigators, field and laboratory staff and participants were blinded to the treatment code until all field data had been collected and preliminary data analysis by coded groups had been completed. Fieldworkers distributed capsules and monitored compliance at the home of the women, resulting in consumption of $70 \%$ of supplements ${ }^{(17)}$.

\section{Definitions}

Growth faltering was defined as a downward change of either weight-for-age or height-for-age percentile crossing two or more major percentile lines (the 5th, 10th, 25th, 50th, 75th, 90th and 95th percentile lines) or $\mathrm{WAZ}<-2 \mathrm{SD}$ (underweight), $\mathrm{HAZ}<-2 \mathrm{SD}$ (stunting) or $\mathrm{WHZ}<-2 \mathrm{SD}$ (wasting) using the WHO 2006 growth curve as reference $^{(21,22)}$. The growth chart of each participating child was reviewed individually and the point and time of downward crossing of two or more major percentile lines were recorded.

Prematurity, low birth weight (LBW) and small for gestational age (SGA) were defined as gestational age $<37$ weeks at birth, birth weight $<2500 \mathrm{~g}$ and birth weight $<10$ th percentile, respectively ${ }^{(23)}$. The definition of ' $1 \mathrm{~d}$ of diarrhoea' indicated three or more liquid or semi-liquid stools, whereas ' $1 \mathrm{~d}$ of respiratory illness' indicated the diagnosis of a child suffering from a runny nose or cough, with or without fever. When estimating the number of days with illness, the fieldworker took into account the $14 \mathrm{~d}$ before the visit. Duration of diarrhoea and respiratory illness included number of illness days during the 3-month period preceding growth faltering; for those who did not falter, a randomly selected 3-month period was used.

Household characteristics with respect to sources of drinking water and sanitation facilities were defined using 
the WHO criteria ${ }^{(24)}$. 'Improved sources of drinking water' included household connections, public standpipes, boreholes, protected dug wells, protected springs and rain water collections, whereas 'unimproved sources' included unprotected wells, unprotected springs, vendor-provided water, bottled water (unless water for other uses was available from an improved source) and tanker truck-provided water. 'Improved sanitation facilities' included connection to public sewers or septic systems, pour-flush latrines and simple or ventilated improved pit latrines, whereas 'unimproved facilities' included service or bucket latrines from which excreta were manually removed, as well as public latrines and open latrines.

\section{Data collection}

At the start of the Zibuvita Study, trained fieldworkers collected identity and socio-economic data from the participating women through home interviews. In addition, anthropometric, dietary and morbidity data on the participating children were collected during home visits. Weight and length data were collected monthly from birth to 12 months of age, and then again at 18 and 24 months of age. Fieldworkers trained in standard anthropometric techniques for children measured weight using a portable electronic scale (Seca 835; CMS Weighing Equipment, London, UK), and length using a locally produced wooden measuring board. Weight was measured with the child completely naked and length was measured with the child in supine position. Measurements were taken in triplicate and mean values were recorded.

Data on breast-feeding practices were collected using the $24 \mathrm{~h}$ recall method: weekly during the first 2 months, biweekly during the third and fourth months, monthly from 5 to 18 months of age and finally at 24 months of age. The number of days with symptoms of diarrhoea and respiratory infections was recorded monthly using questionnaires in which the parents were asked for occurrence of symptoms of diarrhoea or respiratory infection on the day of visit by the fieldworker, followed by the same questions for the day before, $2 \mathrm{~d}$ before and so forth until $14 \mathrm{~d}$ before the visit.

\section{Data entry and statistical analysis}

Analyses were conducted using the Statistical Package for the Social Sciences statistical software package version $15 \cdot 0$ (SPSS Inc., Chicago, IL, USA). Anthropometric data were transformed into $Z$-scores using EpiInfo version 3.3 (Centers for Disease Control and Prevention, Atlanta, GA, USA) and then imported to SPSS for statistical analysis. Imputations for missing values of length (16\%) were carried out by assuming a linear growth pattern; for example, we imputed missing length data at 9 months of age as

$$
\text { [(length at } 8 \text { months + length at } 10 \text { months)/2]. }
$$

Differences between supplementation groups for dichotomous data or proportions were tested using the $\chi^{2}$ test. ANOVA was performed to test comparability of continuous data. Two-way ANOVA was used to test the main effects and interaction of vitamin A or Zn supplementation on WAZ, HAZ and WHZ at 0, 3, 6, 9, 12, 18 and 24 months, as well as the absolute and relative weight and length growth rates from birth up to 24 months of age. ANCOVA was subsequently used to adjust for possible confounders and effect modifiers of prenatal supplementation on postnatal child growth. Statistical significance was set at $P<0.05$ and twosided hypothesis tests were used unless specified. To identify the determinants of time to first growth faltering, Cox's proportional hazard function was used and hazard ratio (HR) and 95\% CI were calculated.

\section{Etbical considerations}

Ethical approval was given by the Ethical Committee of the Medical School at Gadjah Mada University in Yogyakarta, Indonesia. Informed consent was obtained from the pregnant women after detailed information was given to the participants.

\section{Results}

\section{Basic characteristics}

There were no differences between the included ( $n$ 343) and not included ( $n$ 1613) women-child pairs with respect to key characteristics such as maternal age $(P=0 \cdot 20)$, height $(P=0 \cdot 09)$ and pre-pregnancy weight $(P=0 \cdot 92)$, nor were there differences with respect to children's sex $(P=0 \cdot 07)$, birth weight $(P=0 \cdot 60)$ and length $(P=0 \cdot 25)$, prevalence of LBW $(P=0 \cdot 57)$, water source $(P=0 \cdot 79)$, sanitation facilities $(P=0 \cdot 90)$ or distribution of prenatal supplementation $(P=0 \cdot 75)$.

Mean maternal age, height, pre-pregnancy weight and pregnancy weight increases were 29 years, $150 \mathrm{~cm}, 46 \mathrm{~kg}$ and $9 \mathrm{~kg}$, respectively. The children's mean birth weight and length were $3.0 \mathrm{~kg}$ and $49 \mathrm{~cm}$, respectively. The prevalence of LBW and small for gestational age was $7 \cdot 0 \%$ and $5 \cdot 2 \%$, respectively. There were no statistically significant differences among supplementation groups with regard to baseline characteristics of mothers, children and households (Table 1).

\section{Growth patterns and impact of prenatal supplementation on growtb}

The growth pattern was similar in boys and girls. The WAZ and HAZ increased slightly from birth to 3 months of age, and thereafter faltered up to 18 months, followed by a slight increase up to 24 months of age. The WHZ decreased continuously from birth to 2 years of age.

Two-factor ANOVA was performed to test the main effects and interaction of prenatal supplementation with vitamin A or Zn. There was a significant main effect of vitamin A on WAZ at 6 months $(P=0 \cdot 04)$ but there were no interaction effects of vitamin $\mathrm{A}$ and $\mathrm{Zn}$, except at 6 months of age $(P=0 \cdot 048$; Table 2$)$. However, this effect 
Table 1 Basic characteristics of the mothers (pregnancy and education), children (perinatal) and household facilities

\begin{tabular}{|c|c|c|c|c|c|c|c|c|}
\hline \multirow[b]{3}{*}{ Characteristic } & \multicolumn{8}{|c|}{ Prenatal supplementation groups } \\
\hline & \multicolumn{2}{|c|}{ Vitamin A ( $n$ 89) } & \multicolumn{2}{|c|}{$\mathrm{Zn}(n 88)$} & \multicolumn{2}{|c|}{ Vitamin A + Zn ( $n$ 86) } & \multicolumn{2}{|c|}{ Placebo $(n 80)$} \\
\hline & Mean & SD & Mean & SD & Mean & SD & Mean & SD \\
\hline \multicolumn{9}{|l|}{ Mothers } \\
\hline Age (years) & $29 \cdot 1$ & $5 \cdot 3$ & $28 \cdot 2$ & $5 \cdot 4$ & $28 \cdot 4$ & $4 \cdot 8$ & $30 \cdot 2$ & $5 \cdot 5$ \\
\hline Parity $(n)$ & $1 \cdot 9$ & $1 \cdot 7$ & $1 \cdot 7$ & $1 \cdot 5$ & $1 \cdot 6$ & $1 \cdot 6$ & $1 \cdot 8$ & $1 \cdot 4$ \\
\hline Pre-pregnancy weight (kg) & $47 \cdot 2$ & $7 \cdot 9$ & $46 \cdot 5$ & $8 \cdot 8$ & $46 \cdot 0$ & $8 \cdot 3$ & $45 \cdot 9$ & $8 \cdot 1$ \\
\hline Increase in weight during pregnancy $(\mathrm{kg})$ & 8.9 & $2 \cdot 3$ & $8 \cdot 6$ & $2 \cdot 5$ & $8 \cdot 3$ & $2 \cdot 7$ & $8 \cdot 8$ & $2 \cdot 9$ \\
\hline Height $(\mathrm{cm})$ & $151 \cdot 0$ & $4 \cdot 5$ & $150 \cdot 0$ & $5 \cdot 2$ & $150 \cdot 0$ & $5 \cdot 4$ & $150 \cdot 0$ & $5 \cdot 0$ \\
\hline \multicolumn{9}{|l|}{ Children } \\
\hline Birth weight (kg) & $3 \cdot 1$ & 0.5 & $3 \cdot 2$ & 0.5 & $3 \cdot 1$ & 0.4 & $3 \cdot 1$ & 0.4 \\
\hline Birth length (cm) & $48 \cdot 9$ & $2 \cdot 4$ & $48 \cdot 8$ & $2 \cdot 2$ & $48 \cdot 7$ & $2 \cdot 0$ & $48 \cdot 7$ & $2 \cdot 4$ \\
\hline \multirow[t]{2}{*}{ Exclusive breast-feeding (months) } & $2 \cdot 8$ & $1 \cdot 4$ & $2 \cdot 6$ & $1 \cdot 4$ & $2 \cdot 8$ & $1 \cdot 4$ & $2 \cdot 6$ & $1 \cdot 3$ \\
\hline & $n$ & $\%$ & $n$ & $\%$ & $n$ & $\%$ & $n$ & $\%$ \\
\hline \multicolumn{9}{|l|}{ Mothers } \\
\hline Illiterate or less educated & 71 & $79 \cdot 7$ & 67 & $77 \cdot 0$ & 60 & $69 \cdot 8$ & 61 & $77 \cdot 2$ \\
\hline \multicolumn{9}{|l|}{ Children } \\
\hline Girls & 44 & $49 \cdot 4$ & 50 & $56 \cdot 8$ & 45 & $52 \cdot 3$ & 39 & $48 \cdot 8$ \\
\hline Low birth weight $(<2.5 \mathrm{~kg})$ & 4 & $4 \cdot 5$ & 8 & $8 \cdot 0$ & 3 & $3 \cdot 5$ & 2 & $2 \cdot 5$ \\
\hline Small for gestational age ${ }^{\star}$ & 3 & $3 \cdot 4$ & 7 & $8 \cdot 0$ & 4 & $4 \cdot 7$ & 4 & $5 \cdot 0$ \\
\hline Prematurity (<37 gestation weeks) & 9 & $10 \cdot 1$ & 4 & $4 \cdot 5$ & 4 & $4 \cdot 7$ & 7 & $8 \cdot 8$ \\
\hline \multicolumn{9}{|l|}{ Household facilities } \\
\hline Unimproved drinking watert & 10 & $11 \cdot 2$ & 11 & $12 \cdot 8$ & 10 & $11 \cdot 6$ & 12 & $15 \cdot 2$ \\
\hline Unimproved sanitation $\ddagger$ & 39 & $43 \cdot 8$ & 37 & $43 \cdot 0$ & 39 & $45 \cdot 3$ & 46 & $58 \cdot 2$ \\
\hline
\end{tabular}

There were no significant differences among the prenatal supplementation groups for any of the background characteristics.

${ }^{*}$ Birth weight $<10$ th percentile.

tUnimproved sources of drinking water according to the WHO criteria ${ }^{(24)}$

fUnimproved sanitation facilities according to the WHO criteria ${ }^{(24)}$.

disappeared after adjusting for birth weight and length and for duration of breast-feeding, diarrhoea and respiratory illness $(P=0 \cdot 67)$.

For HAZ, two-factor ANOVA showed a significant main effect of $\mathrm{Zn}$ at 6 months $(P=0 \cdot 002)$ and significant negative interaction between vitamin $\mathrm{A}$ and $\mathrm{Zn}$ at 9, 12 and 18 months of age $(P=0.03, P=0.04$ and $P=0.02$, respectively; Table 2); however, after controlling for covariates, the difference in HAZ at 3 months became significant $(P=0.03)$ and the differences at $9(P=0.04)$ and $18(P=0 \cdot 04)$ months of age remained statistically significant. The absolute differences between the vitaminA only and vitamin A + Zn groups at 3 and 9 months were $0.34 \mathrm{SD}$ and $0.37 \mathrm{SD}$, respectively, and the absolute difference between the vitamin A-only and Zn-only groups at 18 months was $0 \cdot 31 \mathrm{sD}$.

Finally, for WHZ, two-factor ANOVA did show a significant main effect of vitamin A $(P=0 \cdot 04)$ at 6 months but no significant interaction effects of prenatal vitamin $A$ and $\mathrm{Zn}$ supplementation. There was no effect of supplementation on growth rate at any age period with regard to weight, height or weight for height (data not shown).

\section{Effects on prevalence of growth faltering}

Growth faltering was more prevalent when defined as downward crossing of two or more major percentile lines compared with growth $<-2$ sD. Using either method, the prevalence of growth faltering increased with age (Figs 2(a) and (b)). The majority of children had crossed two or more major percentile lines by 9 months of age. Prenatal supplementation did not affect the risk of growth faltering. Birth length was the only covariate to be significantly associated with this risk in the present study. An increase in birth length of $1 \mathrm{~cm}$ reduced the risk of growth faltering by $9 \%(\mathrm{HR}=0 \cdot 910 ; 95 \% \mathrm{CI} 0 \cdot 831,0 \cdot 997$; Table 3).

\section{Discussion}

In the present study we found no effect on postnatal child growth from prenatal supplementation with either vitamin $\mathrm{A}$, a combination of vitamin $\mathrm{A}$ and $\mathrm{Zn}$, or $\mathrm{Zn}$ alone, compared with placebo. However, there was a positive effect of vitamin A supplementation alone on subsequent length of children in comparison with a combination of vitamin $\mathrm{A}$ and $\mathrm{Zn}$ or with supplementation with $\mathrm{Zn}$ only. The effects were small, ranging from 0.31 to $0.37 \mathrm{sD}$, and inconsistent, as they appeared only at certain ages, that is, at 3,9 and 18 months, but not at the other time points measured, including birth. In addition, the effects were seen only at the cross-sectional monthly measurements of HAZ, with no effects over time on growth rate or on any of the other anthropometric measurements. Furthermore, the prenatal supplements did not prevent the development of growth faltering. 
Table 2 Impact of prenatal vitamin A and zinc supplementation on child WAZ, HAZ and WHZ at 0, 3, 6, 9, 12, 18 and 24 months of age

\begin{tabular}{|c|c|c|c|c|c|c|c|c|c|c|c|c|c|c|c|}
\hline \multirow[b]{3}{*}{ Months } & \multirow[b]{3}{*}{$n$} & \multicolumn{8}{|c|}{ Prenatal supplementation groups } & \multicolumn{3}{|c|}{ ANOVA } & \multicolumn{3}{|c|}{ ANCOVA* $^{*}$} \\
\hline & & \multicolumn{2}{|c|}{ Vitamin A } & \multicolumn{2}{|c|}{$\mathrm{Zn}$} & \multicolumn{2}{|c|}{ Vitamin A + Zn } & \multicolumn{2}{|c|}{ Placebo } & \multicolumn{2}{|c|}{$P$ for main effect } & \multirow{2}{*}{$\begin{array}{c}P \text { for vitamin } \mathrm{A} \times \mathrm{Zn} \\
\text { interaction }\end{array}$} & \multicolumn{2}{|c|}{$P$ for main effect } & \multirow{2}{*}{$\begin{array}{l}P \text { for vitamin } \mathrm{A} \times \mathrm{Zn} \\
\text { interaction }\end{array}$} \\
\hline & & Mean & SD & Mean & SD & Mean & SD & Mean & SD & Vitamin At & $Z n \ddagger$ & & Vitamin At & $Z n \ddagger$ & \\
\hline \multicolumn{16}{|l|}{ WAZ } \\
\hline 0 & 320 & -0.71 & 0.81 & -0.51 & 0.87 & -0.74 & 0.77 & -0.62 & $0 \cdot 81$ & 0.09 & $0 \cdot 70$ & 0.46 & 0.09 & $0 \cdot 19$ & 0.93 \\
\hline 3 & 342 & 0.26 & 0.86 & 0.04 & 0.95 & 0.04 & 0.83 & 0.03 & $0 \cdot 89$ & 0.23 & 0.27 & $0 \cdot 26$ & 0.06 & $0 \cdot 10$ & 0.43 \\
\hline 6 & 330 & $-0 \cdot 15$ & 0.93 & -0.46 & $1 \cdot 14$ & -0.47 & $0 \cdot 88$ & -0.57 & 1.04 & 0.07 & 0.34 & $0.048 \S$ & 0.04 & 0.50 & 0.67 \\
\hline 9 & 320 & -0.85 & 0.94 & $-1 \cdot 20$ & $1 \cdot 15$ & $-1 \cdot 20$ & 0.93 & $-1 \cdot 15$ & $1 \cdot 04$ & $0 \cdot 19$ & 0.07 & $0 \cdot 19$ & $0 \cdot 14$ & $0 \cdot 05$ & $0 \cdot 27$ \\
\hline 12 & 320 & $-1 \cdot 39$ & $1 \cdot 07$ & $-1 \cdot 56$ & $1 \cdot 15$ & $-1 \cdot 74$ & 0.91 & $-1 \cdot 64$ & $1 \cdot 07$ & $0 \cdot 80$ & 0.26 & 0.07 & 0.63 & $0 \cdot 12$ & $0 \cdot 16$ \\
\hline 18 & 331 & $-1 \cdot 79$ & 1.09 & $-2 \cdot 05$ & $1 \cdot 14$ & $-2 \cdot 15$ & 0.98 & $-2 \cdot 03$ & 1.07 & 0.58 & $0 \cdot 11$ & $0 \cdot 15$ & 0.29 & $0 \cdot 10$ & 0.22 \\
\hline 24 & 319 & $-1 \cdot 68$ & 1.04 & -1.95 & $1 \cdot 13$ & $-2 \cdot 07$ & 0.98 & -1.91 & 1.02 & 0.62 & 0.06 & $0 \cdot 12$ & 0.34 & $0 \cdot 16$ & $0 \cdot 25$ \\
\hline \multicolumn{16}{|l|}{ HAZ } \\
\hline 0 & 343 & -0.40 & 0.92 & -0.39 & 0.91 & -0.46 & $0 \cdot 80$ & -0.46 & $1 \cdot 01$ & 0.98 & 0.94 & 0.49 & $0 \cdot 26$ & 0.29 & 0.55 \\
\hline 3 & 343 & 0.14 & 0.84 & 0.00 & 0.95 & -0.20 & 0.92 & 0.00 & 0.93 & 0.78 & 0.08 & 0.08 & 0.72 & $0 \cdot 11$ & $0.03+t$ \\
\hline 6 & 343 & -0.08 & $0 \cdot 77$ & -0.33 & 0.94 & -0.46 & 0.74 & -0.24 & 0.93 & $0 \cdot 84$ & 0.01 & $0 \cdot 12$ & $0 \cdot 81$ & 0.002 & $0 \cdot 17$ \\
\hline 9 & 343 & -0.49 & 0.85 & -0.66 & 0.98 & $-0 \cdot 86$ & 0.84 & -0.74 & 1.02 & $0 \cdot 86$ & $0 \cdot 15$ & $0.03 \|$ & 0.64 & $0 \cdot 11$ & $0 \cdot 04 \ddagger \ddagger$ \\
\hline 12 & 343 & -0.76 & 0.87 & -0.88 & 1.00 & $-1 \cdot 06$ & $0 \cdot 70$ & -0.99 & 0.97 & 0.77 & 0.30 & 0.04 & 0.62 & $0 \cdot 21$ & 0.06 \\
\hline 18 & 343 & $-1 \cdot 17$ & 0.99 & $-1 \cdot 77$ & 0.92 & $-1 \cdot 48$ & 0.81 & $-1 \cdot 33$ & 0.90 & 0.46 & 0.42 & $0.02^{\star *}$ & 0.85 & 0.49 & $0.04 \$ \S$ \\
\hline 24 & 343 & $-1 \cdot 17$ & $1 \cdot 01$ & $-1 \cdot 06$ & $1 \cdot 00$ & $-1 \cdot 41$ & $0 \cdot 87$ & $-1 \cdot 20$ & 0.98 & $0 \cdot 12$ & 0.64 & 0.07 & $0 \cdot 33$ & $0 \cdot 85$ & $0 \cdot 15$ \\
\hline \multicolumn{16}{|l|}{ WHZ } \\
\hline 0 & 304 & -0.16 & 1.05 & 0.12 & 1.04 & -0.01 & 1.00 & 0.04 & $1 \cdot 21$ & $0 \cdot 18$ & 0.34 & $0 \cdot 80$ & 0.68 & 0.73 & 0.42 \\
\hline 3 & 342 & -0.04 & $1 \cdot 00$ & -0.21 & $1 \cdot 06$ & 0.08 & 0.97 & -0.24 & $1 \cdot 36$ & 0.04 & 0.53 & $0 \cdot 71$ & 0.06 & 0.97 & 0.25 \\
\hline 6 & 330 & 0.01 & 0.92 & $-0 \cdot 16$ & 1.07 & 0.01 & 0.92 & -0.34 & $1 \cdot 17$ & 0.03 & 0.43 & 0.40 & 0.04 & 0.50 & 0.67 \\
\hline 9 & 320 & -0.20 & 1.05 & -0.59 & 1.09 & -0.35 & 1.04 & -0.45 & $1 \cdot 10$ & 0.04 & 0.23 & 1.00 & 0.08 & $0 \cdot 19$ & 0.77 \\
\hline 12 & 320 & -0.65 & $1 \cdot 14$ & -0.74 & $1 \cdot 08$ & -0.77 & 1.00 & -0.74 & $1 \cdot 13$ & 0.79 & 0.60 & 0.62 & 0.77 & 0.48 & 0.99 \\
\hline 18 & 331 & -0.85 & 1.05 & $-1 \cdot 21$ & 1.05 & $-1 \cdot 04$ & $1 \cdot 05$ & -1.07 & $1 \cdot 13$ & $0 \cdot 10$ & $0 \cdot 16$ & 0.82 & $0 \cdot 10$ & $0 \cdot 12$ & 0.94 \\
\hline 24 & 319 & -1.09 & 1.09 & $-1 \cdot 44$ & $1 \cdot 14$ & $-1 \cdot 34$ & $1 \cdot 00$ & $-1 \cdot 37$ & 1.01 & $0 \cdot 10$ & $0 \cdot 18$ & 0.43 & 0.08 & 0.31 & 0.45 \\
\hline
\end{tabular}

WAZ, weight-for-age Z-score; HAZ, height-for-age Z-score; WHZ, weight-for-height Z-score.

${ }^{*}$ Covariates: birth weight, birth length, exclusive breast-feeding duration, duration of diarrhoea and duration of respiratory illness. +Vitamin $A$ v. Zn and placebo.

$\$ Z n$. vitamin $A$ and placebo.

Significant difference between the vitamin $A$ and vitamin $A+Z n$ groups (ANOVA $P<0.05$ ).

- Significant difference between the vitamin $A$ and vitamin $A+Z n$ groups (ANOVA $P<0.05$ ).

${ }^{*}$ Significant difference between the vitamin $A$ and $Z n$ groups (ANOVA $P<0 \cdot 05$ ).

$t+$ Significant difference between the vitamin $A$ and vitamin $A+Z n$ groups (ANCOVA $P<0.005$ ).

\#¥Significant difference between the vitamin $A$ and vitamin $A+Z n$ groups (ANCOVA $P<0 \cdot 05$ ).

$\$ \$ S i g n i f i c a n t$ difference between the vitamin $A$ and $Z n$ groups (ANCOVA $P<0 \cdot 05$ ). 
The minor effects of prenatal vitamin A and/or Zn supplementation on growth indicate that intra-uterine growth is influenced by multiple factors and complex mechanisms. The prevalence of vitamin A, Zn and Fe deficiency among the pregnant women at the present study site indicates multiple micronutrient shortages, possibly reducing the effects of any single supplement ${ }^{(17)}$. On the other hand, the vitamin A deficiency prevalence of $5 \%$, indicating only a mild public health impact, may have been insufficient to respond to supplementation. Postnatal vitamin A supplementation has improved growth where endemic deficiency exists ${ }^{(25)}$. The low prevalence of SGA and LBW compared with that in many other low-income settings may indicate that the fetal nutritional status in the present population was sufficiently good to not respond to prenatal supplementation.

In progeny, maternal vitamin A deficiency has been related to LBW, indicating intra-uterine growth retardation,

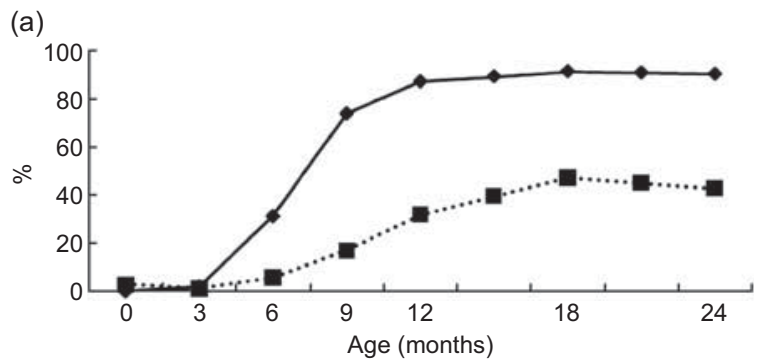

(b)

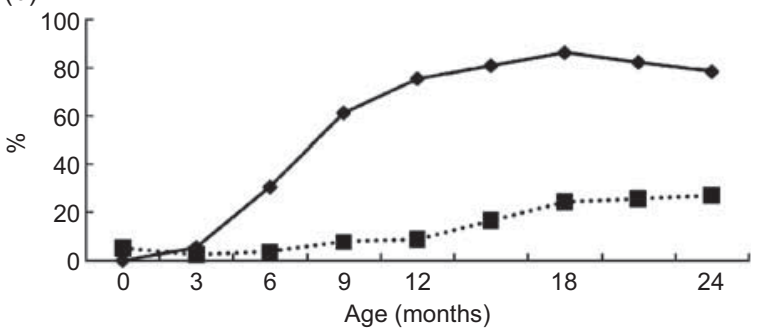

Fig. 2 Prevalence of growth faltering up to 2 years of age, defined as either crossing two or more percentile lines (or growth $<-2$ SD below the reference population $(\cdot \cdot \cdot \cdot \cdot)$ for weight-for-age (a) and height-for-age (b). increased morbidity and poor growth or stunting until 6 months of age ${ }^{(26)}$. From animal studies it has been hypothesized that vitamin A stimulates growth by a direct role in cell replication ${ }^{(27)}$. In rodents, moderate vitamin A deficiency during pregnancy has been reported to reduce lung weight and muscle development in the offspring ${ }^{(28)}$. $\mathrm{Zn}$ is essential for the activity of over 300 enzymes involved in processes such as mitosis, DNA synthesis and gene activation and expression. Approximately $82 \%$ of pregnant women worldwide are likely to have inadequate $\mathrm{Zn}$ intake ${ }^{(29)}$. Animal studies have shown that mean values of birth weight, birth length and tail length were lower in litters from $\mathrm{Fe}$ - or $\mathrm{Zn}$-deficient dams ${ }^{(30)}$. In addition, providing postnatal $\mathrm{Zn}$ supplementation to $\mathrm{Zn}$ deficient children has been shown to improve growth ${ }^{(21)}$.

Studies on the effects of prenatal supplementation with vitamin $\mathrm{A}, \mathrm{Zn}$ or multiple micronutrient combinations containing either vitamin A or $\mathrm{Zn}$ on infant growth have shown inconsistent results. Several studies from Nepal have investigated the effects of micronutrient supplementation during pregnancy on outcomes in children. Osrin et al. $^{(31)}$ supplemented pregnant women with fifteen micronutrients and minerals, including vitamin A and $\mathrm{Zn}$, and reported increased birth weight compared with supplementation with vitamin A alone, whereas Katz et al. ${ }^{(32)}$ reported not only higher birth weight but also a change in birth weight distribution as a result of certain combinations of antenatal supplementation. A follow-up of the latter study population showed a lingering positive impact of maternal Fe, folic acid and Zn supplementation on height and subcutaneous fat at 6-8 years of age ${ }^{(33)}$. A follow-up study by Vaidya et $\mathrm{al}^{(34)}$ on $2 \cdot 5$-year-olds showed that weight, head, chest and mid-arm circumference and triceps skin folds remained higher in the multiple micronutrient group, but with no effect on height, compared with $\mathrm{Fe}+$ folic acid supplementation during pregnancy. The benefits of prenatal multiple micronutrient supplementation on birth size, neonatal morbidity and mortality and later growth have also been shown in studies conducted in other developing countries ${ }^{(35-39)}$. In one meta-analysis, reduction of LBW was found among infants of mothers prenatally supplemented with multiple micronutrients compared with

Table 3 Risk for growth faltering in relation to some potential risk factors in children from prenatally supplemented mothers in rural Java, Indonesia, analysed using Cox proportional hazard regression

\begin{tabular}{|c|c|c|c|c|c|c|}
\hline \multirow[b]{2}{*}{ Covariates } & \multicolumn{2}{|c|}{ Weight-for-age } & \multicolumn{2}{|c|}{ Height-for-age } & \multicolumn{2}{|c|}{ Weight-for-height } \\
\hline & $\mathrm{HR}$ & $95 \% \mathrm{Cl}$ & $\mathrm{HR}$ & $95 \% \mathrm{Cl}$ & $\mathrm{HR}$ & $95 \% \mathrm{Cl}$ \\
\hline Supplementation type & 0.97 & $0.701,1 \cdot 33$ & 1.07 & $0.776,1.48$ & $1 \cdot 17$ & $0.833,1.63$ \\
\hline Gender & 0.92 & $0 \cdot 697,1 \cdot 20$ & $0 \cdot 88$ & $0.669,1 \cdot 16$ & $0 \cdot 91$ & $0 \cdot 693,1 \cdot 20$ \\
\hline Birth weight (kg) & $1 \cdot 32$ & $0 \cdot 868,2 \cdot 02$ & $1 \cdot 00$ & $0.670,1.50$ & $1 \cdot 04$ & $0 \cdot 676,1 \cdot 60$ \\
\hline Birth length $(\mathrm{cm})$ & 0.99 & $0.907,1.08$ & $1 \cdot 03$ & $0.946,1 \cdot 12$ & $0 \cdot 91$ & $0.831,1.00$ \\
\hline Exclusive breast-feeding duration (months) & $1 \cdot 03$ & $0.933,1.14$ & 0.99 & $0.898,1.09$ & $1 \cdot 01$ & $0 \cdot 910,1 \cdot 12$ \\
\hline Duration of diarrhoea* & $1 \cdot 02$ & $0 \cdot 943,1 \cdot 10$ & $1 \cdot 05$ & $0.978,1 \cdot 14$ & 0.97 & $0 \cdot 899,1 \cdot 06$ \\
\hline Duration of respiratory illness* & 0.98 & $0.963,1.00$ & $1 \cdot 00$ & $0.981,1.02$ & 0.99 & $0 \cdot 970,1 \cdot 01$ \\
\hline
\end{tabular}

$H R$, hazard ratio.

${ }^{*}$ Duration of illness before growth faltering was initially identified. 
placebo or Fe and folic acid ${ }^{(40)}$, whereas other meta-analyses or reviews concluded no added benefits of multiple micronutrient or Zn supplementation on birth weight ${ }^{(41,42)}$.

The interpretation of these results, in relation to ours, is that composition and dosage of micronutrients as well as the time during pregnancy when supplements are introduced are crucial for infant growth and may explain the differences seen with different micronutrient and supplementation regimes.

Interactions between vitamin $\mathrm{A}$ and $\mathrm{Zn}$ may have decreased the effects of prenatal supplementation on growth in the present study. Children of mothers supplemented with the combined vitamin A and $\mathrm{Zn}$ supplement were shorter than those who were supplemented with vitamin A only at certain ages. We have no measure of either vitamin A or Zn status of mothers after supplementation; hence, we cannot say whether this interaction was evident in mothers as well. Interactions between vitamin A and Zn during pregnancy have been shown in animal studies. One study showed an increase in hepatic vitamin A concentration in fetuses when dams were fed decreasing amounts of $\mathrm{Zn}$, reflecting impaired mobilization of vitamin A. Another study on pregnant rhesus monkeys showed that, above a certain threshold of plasma $\mathrm{Zn}$, vitamin A transport was not dependent on plasma $\mathrm{Zn}$ concentration but that, below the threshold, vitamin A release and transport from the liver was strongly influenced by plasma $\mathrm{Zn}$ concentrations. In humans, very few studies have shown interactions between vitamin A and $\mathrm{Zn}$. One study indicated a weak and non-significant correlation between liver $\mathrm{Zn}$ and vitamin A content in fetuses and stillborn infants and in infants who died within the first 4 months of life ${ }^{(43)}$. These studies shed little light on our findings as, although the women were supplemented with both vitamin A and $\mathrm{Zn}$, their progeny grew less well. Therefore, the conflicting results of the present study should be interpreted with caution, requiring biological explanations unavailable at this time; they may also indicate chance findings.

In the present study, using downward crossing of two or more major percentile lines as the marker for growth faltering, a substantial proportion of children had signs of faltering in weight and height before 6 months of age, and the majority of children were faltered by 9 months of age. Stunting and wasting among children under 5 years of age are associated with significant morbidity and mortality throughout life ${ }^{(44,45)}$. In our study, the prevalence of growth faltering was lower if WAZ or HAZ $<-2$ SD was used. Therefore, crossing major percentile lines may be an earlier sign of growth faltering compared with reaching $Z$-scores $<-2$ SD and may offer opportunities for earlier intervention to reverse the faltering growth trend.

The small but positive effects of prenatal vitamin A supplementation on child growth in our study add to a body of conflicting results with regard to maternal supplementation studies, suggesting that more research is required. The children in the present study were born to mothers recruited to an individually randomized, placebocontrolled, double-masked, community-based trial conducted in a rural area with high incidence of micronutrient deficiencies among pregnant women. The adherence to the supplementation scheme (70\%) was high. All outcomes, data on breast-feeding practices and symptoms of infectious diseases, which were potential confounders or effect modifiers, were collected prospectively until 24 months of age. Previous studies have indicated that birth weight and length ${ }^{(46,47)}$, breast-feeding ${ }^{(48)}$ and child morbidity, especially diarrhoea ${ }^{(44,49)}$ and respiratory illness ${ }^{(50,51)}$, are factors that may affect postnatal growth. After controlling for these covariates, the associations between prenatal vitamin A on child growth remained significant.

A limiting factor in our study was the large loss to follow-up from the initial study to the present. Out of the 1956 live births from the women participating in the Zibuvita Study, only 343 could be included in the final analysis. However, we found no statistically significant differences with respect to key characteristics between these children and those not included. Moreover, the original sample size itself may have been too small to detect growth differences of public health importance. The effects of prenatal supplementation on symptoms of infectious diseases, which can modify the effects on growth, may also have been underestimated, since methods using recall may under-report symptoms of disease, as shown in an Indian study ${ }^{(52)}$. Nevertheless, all supplementation groups were followed up in a similar manner, which should have adjusted for at least large intergroup variations. Future studies on the impact of prenatal supplementation should clarify the mechanisms and effects of actions and interactions of micronutrients, alone or in combination, on postnatal child growth, bringing deeper understanding to the public health benefits of prenatal supplementation, as well as better tools to prevent childhood growth faltering from the earliest possible date.

In conclusion, the present study shows no effect of prenatal supplementation with either vitamin A or a combination of vitamin A and $\mathrm{Zn}$, or with $\mathrm{Zn}$ alone, compared with placebo, on postnatal child growth. However, there was a positive effect of vitamin A supplementation alone on subsequent length of children, compared with a combination of vitamin $\mathrm{A}$ and $\mathrm{Zn}$ or supplementation with Zn only, but without an effect on other anthropometric measures, growth rate or prevalence of growth faltering. Future studies should duplicate these findings before recommendations on prenatal vitamin A supplementation can be made. Using downward crossing of two or more major percentile lines as the definition of growth faltering, the findings indicate that a substantial proportion of children in the study showed signs of poor growth and at an earlier age than seen using a definition of $Z$-scores $<-2 \mathrm{sD}$. 


\section{Acknowledgements}

The present study was supported by grants from MotherCare, John Snow Inc., Washington, DC, USA, and from UNICEF, Jakarta, Indonesia, to the Gadjah Mada University and to the University of Newcastle, Newcastle, Australia. Infrastructure support was provided by the Community Health and Nutrition Research Laboratories (CHN-RL), Faculty of Medicine, Gadjah Mada University and by the Ministry of Health, Republic of Indonesia, through the Third Community Health and Nutrition Development Project Loan from the World Bank (IBRD loan no. 3550IND). The present study was partly undertaken within the Centre for Global Health at Umeå University, with support from Forskningsrådet för arbetsliv och socialvetenskap (FAS), the Swedish Council for Working Life and Social Research (2006-1512). The authors have no conflict of interest to declare. E.P.P. analysed the data and wrote the manuscript; T.L., L.N., A.I. and H.S. supported the data analysis and contributed to the development of the manuscript. The authors are grateful to Professor Mohammad Hakimi, Department of Obstetrics and Gynaecology and CHN-RL, Medical School, Gadjah Mada University, and to Michael J. Dibley, Senior Lecturer in Epidemiology, Faculty of Medicine and Health Sciences, Centre for Clinical Epidemiology and Biostatistics, School of Population Health, University of Newcastle, Callaghan, NSW, Australia, for providing the Zibuvita data. They also thank Dr Detty S. Nurdiati, Department of Obstetrics and Gynaecology, Professor Djauhar Ismail, Division of Growth and Development, Department of Child Health, and Ekawaty L. Haksari, Division of Perinatology, Department of Child Health, all at Medical School, Gadjah Mada University, Yogyakarta, Indonesia, for their comments on the manuscript, and Muhammad Arifin, CHN-RL, for data preparation.

\section{References}

1. Black RE, Allen RH, Bhutta ZA et al. (2008) Maternal and child undernutrition: global and regional exposures and health consequences. Lancet 371, 243-260.

2. World Health Organization (2009) Global database on child growth and malnutrition - Indonesia. http://www.who.int/ nutgrowthdb/database/countries/who_standards/idn.pdf (accessed August 2009).

3. Pelletier DL \& Frongillo EA (2003) Changes in child survival are strongly associated with changes in malnutrition in developing countries. J Nutr 133, 107-119.

4. Drewett RF, Corbett SS \& Wright CM (1999) Cognitive and educational attainments at school age of children who failed to thrive in infancy: a population-based study. J Child Psychol Psychiatry 40, 551-561.

5. Mendez MA \& Adair LS (1999) Severity and timing of stunting in the first two years of life affect performance on cognitive tests in late childhood. J Nutr 129, 1555-1562.

6. Barker DJP (1998) Mothers, Babies and Health in Later Life, 2nd ed., pp. 43-62 and 97-115. Edinburgh: Churchill Livingstone.

7. Blair PS, Drewett RF, Emmett PM et al. (2004) Family, socioeconomic and prenatal factors associated with failure to thrive in the Avon Longitudinal Study of Parents and Children (ALSPAC). Int J Epidemiol 33, 839-847.

8. Castillo-Duran C \& Weisstaub G (2003) Zinc supplementation and growth of the fetus and low birth weight infant. J Nutr 133, Suppl., 1494S-1497S.

9. King JC (2000) Determinant of maternal zinc status during pregnancy. Am J Clin Nutr 71, Suppl., 1334S-1343S.

10. Fenster L, Eskenazi B, Windham GC et al. (1991) Caffeine consumption during pregnancy and fetal growth. Am J Public Health 81, 458-461.

11. CARE Study Group (2008) Maternal caffeine intake during pregnancy and risk of fetal growth restriction: a large prospective observational study. BMJ 337, a2332.

12. Nordentoft M, Lou HC, Hansen D et al. (1996) Intrauterine growth retardation and premature delivery: the influence of maternal smoking and psychosocial factors. Am J Public Health 86, 347-354.

13. Müller O \& Kravinkel M (2005) Malnutrition and health in developing countries. CMAJ 173, 279-286.

14. Hambidge KM, Abebe Y, Gibson RS et al. (2006) Zinc absorption during late pregnancy in rural southern Ethiopia. Am J Clin Nutr 84, 1102-1106.

15. Merialdi M, Caulfield LE, Zavaleta $\mathrm{N}$ et al. (2004) Randomized controlled trial of prenatal zinc supplementation and fetal bone growth. Am J Clin Nutr 79, 826-830.

16. Hafeez A, Mehmood G \& Mazhar F (2005) Oral zinc supplementation in pregnant women and its effect on birth weight: a randomised controlled trial. Arch Dis Child Fetal Neonatal Ed 90, F170-F171.

17. Persson V, Hartini TN, Greiner T et al. (2002) Vitamin A intake is low among pregnant women in central Java, Indonesia. Int J Vitam Nutr Res 72, 124-132.

18. Winkvist A, Stenlund H, Hakimi M et al. (2002) Weight-gain patterns from prepregnancy until delivery among women in Central Java, Indonesia. Am J Clin Nutr 75, 1072-1077.

19. Lind T, Lönnerdal B, Stenlund H et al. (2003) A communitybased randomized controlled trial of iron and zinc supplementation in Indonesian infants: interactions between iron and zinc. Am J Clin Nutr 77, 883-890.

20. Lind T, Lönnerdal B, Stenlund $\mathrm{H}$ et al. (2004) A communitybased randomized controlled trial of iron and zinc supplementation in Indonesian infants: effects on growth and development. Am J Clin Nutr 80, 729-736.

21. Olsen EM (2006) Failure to thrive: still a problem of definition. Clin Pediatr 45, 1-6.

22. Administrative Committee on Coordination/Subcommittee on Nutrition (2000) Fourth Report on the World Nutrition Situation. Geneva, Switzerland: ACC/SCN in collaboration with IFPRI.

23. Lubchenco LO, Hansman C \& Boyd E (1966) Intrauterine growth length and head circumference as estimated from live birth at gestational ages from 26 to 42 weeks. Pediatrics 37, 403-408.

24. WHO Statistical Information System (2008) Access to improved drinking water sources and to improved sanitation. http://www.who.int/whosis/indicators/compendium/ 2008/2wst/en/index/html (accessed August 2009).

25. West KP, Djunaedi E, Pandji A et al. (1988) Vitamin A supplementation and growth: a randomized community trial. Am J Clin Nutr 48, 1257-1264.

26. Tielsch JM, Rahmathullah L, Katz J et al. (2008) Maternal night blindness during pregnancy is associated with low birth weight, morbidity, and poor growth in south India. J Nutr 138, 787-792.

27. Zile MH, Bunge EC \& DeLuca HF (1979) On the physiological basis of vitamin A-stimulated growth. J Nutr 109, 1787-1796.

28. Downie D, Antipatis C, Delday MI et al. (2005) Moderate maternal vitamin A deficiency alters myogenic regulatory protein expression and perinatal organ growth in the rat. Am J Physiol Regul Integr Comp Physiol 288, R73-R79. 
29. Osendarp SJM, West CE \& Black RE (2003) The need for maternal zinc supplementation in developing countries: an unresolved issue. J Nutr 133, 817S-827S.

30. Shahbazi M, Naghdi W, Tahmaseli S et al. (2009) The effect of iron and zinc dietary restriction of pregnant rats on physical growth of litters. Biol Trace Elem Res 128, 232-238.

31. Osrin D, Vaidya A, Shrestha Y et al. (2005) Effects of antenatal multiple micronutrient supplementation on birth weight and gestational duration in Nepal: double-blind, randomized controlled trial. Lancet 365, 955-962.

32. Katz J, Christian P, Dominici F et al. (2006) Treatment effects of maternal micronutrient supplementation vary by percentiles of birth weight distribution in rural Nepal. J Nutr 136, 1389-1394.

33. Stewart CP, Christian P, LeClerq SC et al. (2009) Antenatal supplementation with folic acid+iron+zinc improves linear growth and reduces peripheral adiposity in school age children in rural Nepal. Am J Clin Nutr 90, 132-140.

34. Vaidya A, Saville N, Shrestha BP et al. (2008) Effects of antenatal multiple micronutrient supplementation on children's weight and size at 2 years of age in Nepal: follow up of a double-blind randomized controlled trial. Lancet 371, 492-499.

35. Gupta P, Ray M, Dua T et al. (2007) Multimicronutrient supplementation for undernourished pregnant women and the birth size of their offspring. Arch Pediatr Adolesc Med 161, 58-64.

36. Iannotti LL, Zavaleta N, León Z et al. (2008) Maternal zinc supplementation and growth in Peruvian infants. Am J Clin Nutr 88, 154-160.

37. Roberfroid D, Huybregts L, Lanou $\mathrm{H}$ et al. (2008) Effects of maternal multiple micronutrient supplementation on fetal growth: a double-blind randomized controlled trial in rural Burkina Faso. Am J Clin Nutr 88, 1330-1340.

38. Zeng L, Cheng Y, Dang $\mathrm{S}$ et al. (2008) Impact of micronutrient supplementation during pregnancy on birth weight, duration of gestation, and perinatal mortality in rural western China: double blind cluster randomized controlled trial. BMJ 337, a2001.

39. Bhutta ZA, Rizvi A, Raza F et al. (2009) A comparative evaluation of multiple micronutrient and iron-folic acid supplementation during pregnancy in Pakistan: impact on pregnancy outcomes. Food Nutr Bull 30, Suppl. 4, S496-S505.
40. Shah PS \& Ohlsson A, on behalf of the Knowledge Synthesis Group on Determinants of Low Birth Weight and Preterm Births (2009) Effects of multimicronutrient supplementation on pregnancy outcomes: a meta-analysis. CMAJ 180, E99-E108.

41. Haider BA \& Bhutta ZA (2006) Multiple-micronutrient supplementation for women during pregnancy (Review). Cochrane Database Syst Rev issue 4, CD004905.

42. Hess SY \& King JC (2009) Effects of maternal zinc supplementation on pregnancy and lactation outcomes. Food Nutr Bull 30, Suppl. 1, S60-S78.

43. Christian P \& West KP Jr (1998) Interactions between zinc and vitamin A: an update. Am J Clin Nutr 68, Suppl., 435s-441S

44. Checkley W, Buckley G, Gilman RH et al. (2008) Multicountry analysis of the effects of diarrhoea on childhood stunting. Int J Epidemiol 37, 816-830.

45. Shrimpton R, Victora CG, De Onis M et al. (2001) Worldwide timing of growth faltering: implications for nutritional interventions. Pediatrics 107, E75.

46. Arifeen SE, Black RE, Caulfield LE et al. (2000) Infant growth patterns in the slum of Dhaka in relation to birth weight, intrauterine growth retardation, and prematurity. Am J Clin Nutr 72, 1010-1017.

47. Schmidt MK, Muslimatun S, West CE et al. (2002) Nutritional status and linear growth of Indonesian infants in West Java are determined more by prenatal environment than by postnatal factors. J Nutr 132, 2202-2207.

48. Villalpando S \& López-Alarcón M (2000) Growth faltering is prevented by breast-feeding in underprivileged infants from Mexico City. J Nutr 130, 546-552.

49. Moore SR, Lima AAM, Conaway MR et al. (2001) Early childhood diarrhea and helminthiases associate with longterm linear growth faltering. Int J Epidemiol 30, 1457-1464.

50. Adair LS \& Guilkey DK (1997) Age-specific determinants of stunting in Filipino children. J Nutr 127, 314-320.

51. Umeta M, West CE, Verhoef $\mathrm{H}$ et al. (2003) Factors associated with stunting in infants aged 5-11 months in the Dodota-Sire district, rural Ethiopia. J Nutr 133, 1064-1069.

52. Ramakrishnan R, Venkatarao T, Koya PK et al. (1998) Influence of recall period on estimates of diarrhoea morbidity in infants in rural Tamil Nadu. Indian J Public Health 42, 3-6. 